(C) 2014 Primary Care Respiratory Society UK. All rights reserved http://dx.doi.org/10.4104/pcri.2014.00012

Prim Care Respir J 2014; 23(1): 4-5

\section{References}

1. Steppuhn H, Langen U, Keil T, Scheidt-Nave C. Chronic disease co-morbidity of asthma and unscheduled asthma care among adults: results of the national telephone health interview survey German Health Update (GEDA) 2009 and 2010 Prim Care Respir J 2014;23(1):22-29. http://dx. doi.org/10.4104/pcrj.2013.00107

2. Commission on Social Determinants of Health, Closing the gap in a generation. Health equity through action on the social determinants of health. 2008, World Health Organisation: Geneva.

3. van den Akker M, Buntinx F, Knottnerus JA. Comorbidity or multimorbidity: what's in a name? A review of literature. Eur J Gen Pract 1996;2:65-70. http://dx.doi.org/10.3109/13814789609162146

4. Barnett, K., S. Mercer, et al. Epidemiology of multimorbidity and implications for health care, research, and medical edication: a cross-sectional study. Lancet 2012;380(9836):37-43. http://dx.doi.org/10.1016/S0140-6736(12)60240-2

5. Guthrie B, Payne K, Alderson P, McMurdo MET, Mercer SW. Adapting clinical guidelines to take account of multimorbidity. BMJ 2012;345:e6341. http://dx.doi.org/10.1136/bmj.e6341

6. Payne RA, Abel GA, Avery AJ, Mercer SW, Roland MO. Is polypharmacy always hazardous? A retrospective cohort analysis using linked electronic health records from primary and secondary care. Br J Clin Pharmacol 2014, Jan 15 [Epub ahead of print] http://dx.doi.org/10.1111/bcp.12292

7. Vik SA, Maxwell CJ, Hogan DB. Measurement, correlates, and health outcomes of medication adherence among seniors. Ann Pharmacother 2004;38:303-12. http://dx.doi.org/10.1345/aph.1D252

8. May C, Montori VM, Mair FS. We need minimally disruptive medicine. BMJ 2009; 339:b2803. http://dx.doi.org/10.1136/bmj.b2803

9. National Institute for Health and Clinical Excellence. Depression in adults with a chronic physical health problem: treatment and management (National Clinical Practice Guideline Number 91 ).

10. Mercer SW, Guthrie B, Furler J, Watt GCM, Hart JT. Multimorbidity and the inverse care law in primary care. BMJ 2012;344:e4152.

http://dx.doi.org/10.1136/bmj.e4152

11. Smith SM, Soubhi H, Fortin M, Hudon C, O'Dowd T. Interventions for improving outcomes in patients with multimorbidity in primary care and community settings: systematic review. BMJ 2012;345:e5205. http://dx.doi.org/10.1136/bmj.e5205

\title{
A golden goal in 2010, and another GOLD in 2014 in primary care, or vice versa
}

\section{See linked article by Boland et al. on pg 30}

\footnotetext{
*Joan B Soriano1, Miguel Román-Rodríguez²

1 Medical Epidemiologist, FISIB-IdISPA Hospital Universitari Son Espases, Palma de Mallorca, Spain

2 General practitioner, Centre de Salut de Son Pizà, Palma de Mallorca, Spain
}

*Correspondence: Dr Joan B Soriano, FISIB-IdISPA Hospital Universitari Son Espases, Unitat Assaigs Clínics Mòdul I, Nivel -1, Despatx 2, Carretera de Valldemossa, 79; 07010 Palma de Mallorca, España

Tel: +34 871205000 Ext 65720 Fax: +34 871206868

E-mail: jbsoriano2@gmail.com

In this issue of the PCRJ, Boland et al. report an assessment of the old and new GOLD COPD classifications using a large cohort obtained from 28 Dutch primary care centres. ${ }^{1}$ In a way, we Spaniards could compare this Dutch GOLD assessment with the goal from Andrés Iniesta who scored deep into extra-time to give Spain victory over the Netherlands in the World Cup final at Soccer City in Johannesburg in $2010^{2}$ after an exciting but goalless first 114 minutes... (see Figure 1, available online at www.thepcrj.org).

On November 16th 2011, the current revision of the GOLD Executive Summary was released in Shanghai, China, ${ }^{3}$ and later published elsewhere. ${ }^{4}$ It presented a new classification of COPD which was intended to provide a better understanding of the impact of the disease on an individual patient than the previous spirometry-only COPD staging. The four previous spirometry categories were reduced to two, and information on exacerbations and symptoms was added to form a three-dimensional patient evaluation.

This new Dutch research' should be commended, as it showcases a true real-life COPD management assessment. The GOLD Committee should be happy to see that more investigators are independently validating their new recommendations, with this study being added to the growing list of replications, most of which show consistent findings. ${ }^{5}$ In a population with generally mild COPD - as it is often the case (but not always) in primary care - Boland et al. conclude that "... the GOLD ABCD groups classification is more closely associated with costs and HRQoL [health-related quality of life] than the GOLD 1234 grades classification. Furthermore, patients with GOLD-C had a better HRQoL than those with GOLD-B but the costs of the two groups did not differ." This is good news indeed for GOLD; the new GOLD ABCD staging relates very well with increasing costs, and also with both disease- and generic-HRQoL. However, even in this primary care population, patient symptoms in groups B and D produce inconsistencies in staging. There are also novel and very important findings here on comorbidities. ${ }^{1}$ GOLD clearly indicates the relevance of COPD comorbidities in their latest updates, and these primary care COPD patients in stages GOLD B and D have more comorbidities, less physical activity and self-efficacy, and more unemployment.

The strengths of this research from Boland et al.' include novelty; there are only a handful of assessments available in primary care, ${ }^{6-9}$ mostly with consistent findings that neither age nor gender should be associated with the GOLD severity distribution. The study also includes a comprehensive cost-associated analysis (which includes travel costs) from a prestigious, experienced group of researchers, as well as very sophisticated statistics (which are not for the mere mortal clinical reader...). There is also a comprehensive online appendix with extensive sub-analyses. All in all, this study ${ }^{1}$ should indeed stimulate 
thinking on patient-centred outcomes, and is a significant step towards personalised medicine.

However, some limitations should also be noted - i.e. representativeness and misdiagnosis. As a true real-world assessment, Boland et al.'s Figure $1^{1}$ indicates that less than half of those approached finally participated, so a non-response study might be welcome. Also it is stated that $29.6 \%$ (575/2006) were found to be misdiagnosed with COPD. It is likely therefore that both issues make an impact on the severity distribution (over 50\% are GOLD A and only 14 COPD participants are GOLD $D_{3}$ ). Heterogeneity among the 28 practices must be expected. In terms of quality of life assessment, there was no CAT score used in this research and the SGRQ has been used as an outcome measure. Such re-categorisation when produced by different methods (e.g. using CAT, or mMRC dyspnoea scale, CCQ, or other), might produce very different groupings, and therefore categories might not be internally consistent. Finally, the working definition of acute exacerbation of COPD is sui generis (i.e. unique).

Meanwhile, some practical questions remain for GPs to answer. Is the new GOLD staging being implemented in primary care? What are the hurdles? Regrettably, after so many years and different versions, there is still no primary care representation included in the GOLD guideline. It has recently been argued that any new treatment algorithm aimed at primary care clinicians should fully involve members of this community in its production, and should be piloted and evaluated rigorously in primary care settings before dissemination. ${ }^{10}$ As per the new Spanish GESEPOC COPD guidelines, ${ }^{11,12}$ a multicomponent assessment of COPD severity (within primary care or elsewhere) should take into account a range of items including spirometry, smoking, exacerbations, health status, and comorbidities. This could be done using multi-component indices such as BMI, airflow Obstruction, Dyspnoea, and Exercise capacity (BODE), or its modifications, or other.

Pooling together Boland et al.'s primary care data ${ }^{1}$ with other COPD GOLD replications obtained in specialised settings will likely be extremely useful, ${ }^{5,13}$ allowing clinically- and very practically-oriented sub-analyses, thus encompassing all respiratory effectiveness assessments. $^{14}$ Already, the current COPD Cohorts Collaborative International Asssessment ( $3 \mathrm{CIA}$ ) initiative, aimed at pooling European and other COPD cohorts, might explore further new, objectivelyobtained respiratory endpoints and thresholds. ${ }^{15}$

Back to the beautiful game; things would be very different if GOLD included primary care players in its team, or if Arjen Robben's clear chance had not been lost in the 68th minute as he left Puyol and Piqué in his wake before "Saint" Casillas smothered the ball with the edge of his right foot. From now onwards, the rest is history to be written...

Conflicts of interest The authors declare that they have no conflicts of interest in relation to this article.
Commissioned article; not externally peer reviewed; accepted 13th February 2014; online 28th February 2014

(C) 2014 Primary Care Respiratory Society UK. All rights reserved

http://dx.doi.org/10.4104/pcrj.2014.00018

Prim Care Respir J 2014; 23(1): 5-6

\section{References}

1. Boland MRS, Tsiachristas A, Kruis AL, Chavannes NL, Rutten-van Mölken MPMH. Are GOLD ABCD groups better associated with health status and costs than GOLD 1234 grades? A cross-sectional study. Prim Care Respir J 2014;23(1):30-37. http://dx.doi.org/ 10.4104/pcrj.2014.00002

2. World Cup Final 2010 Highlights Spain vs Netherlands (Espana vs Netherlands) http://www.youtube.com/watch?v=NTIIZoGp68l

3. GOLD press release. Summary handout of a GOLD conference sponsored by the Asian Pacific Society of Respirology in Shanghai, China, November 6, 2011. [Accessed on April 10th, 2013 at http://www.goldcopd.org/uploads/users/files/ GOLD2011_Summary.pdf ]

4. Vestbo J, Hurd SS, Agustí AG, et al. Global Strategy for the Diagnosis, Management, and Prevention of Chronic Obstructive Pulmonary Disease: GOLD Executive Summary. Am J Respir Crit Care Med 2013;187:347-65. http://dx.doi.org/10.1164/rccm.201204-0596PP

5. Soriano JB. The GOLD Rush. Thorax 2013;68(10):902-03. http://dx.doi.org/10.1136/thoraxjnl-2013-203595

6. Haughney J, Gruffydd-Jones K, Roberts J, Lee AJ, Hardwell A, McGarvey L. The distribution of COPD in UK general practice using the new GOLD classification. Eur Respir J 2013 Epub Oct 31, erj 00650-2013.

http://dx.doi.org/10.1183/09031936.00065013

7. Jones PW, Nadeau G, Small M, Adamek L. Characteristics of a COPD population categorised using the GOLD framework by health status and exacerbations. Respir Med 2014;108(1):129-35. http://dx.doi.org/10.1016/j.rmed.2013.08.015

8. Punekar YS, Shukla A, Müllerova H. COPD management costs according to the frequency of COPD exacerbations in UK primary care. Int J Chron Obstruct Pulmon Dis 2014;9:65-73. http://dx.doi.org/10.2147/COPD.S54417

9. Maio S, Baldacci S, Martini F, et al. on behalf of the COMODHES study group. COPD management according to old and new GOLD guidelines: an observational study with Italian general practitioners. Curr Med Res Opin 2014. Epub Feb 3. http://dx.doi.org/10.1185/03007995.2014.884492

10. Jones R, Price D, Chavannes N, et al. GOLD COPD categories are not fit for purpose in primary care. Lancet Respir Med 2013;1(1):e17.

http://dx.doi.org/10.1016/\$2213-2600(13)70015-8 Epub 2013 Mar 4. No abstract available.

11. Grupo de Trabajo de GesEPOC . Guía de Práctica Clínica para el Diagnóstico y Tratamiento de Pacientes con Enfermedad Pulmonar Obstructiva Crónica (EPOC) Guía Española de la EPOC (GesEPOC). Arch Bronconeumol 2012;48( suppl 1):1-83.

12. Miravitlles $M$, Soler-Cataluña JJ, Calle $M$, et al. A new approach to grading and treating COPD based on clinical phenotypes: summary of the Spanish COPD guidelines (GesEPOC). Prim Care Respir J 2013;22(1):117-21. http://dx.doi.org/10.4104/pcrj.2013.00016

13. Riley RD, Lambert PC, Abo-Zaid G. Meta-analysis of individual participant data: rationale, conduct, and reporting. BMJ 2010;340:c221. http://dx.doi.org/10.1136/bmj.c221.

14. Roche N, Reddel HK, Agusti A, et al. Respiratory Effectiveness Group. Integrating real-life studies in the global therapeutic research framework. Lancet Respir Med 2013;1(10):e29-30. http://dx.doi.org/10.1016/\$2213-2600(13)70199-1

15. Almagro $P$, Martinez-Camblor $P$, Soriano $B$ et al. Finding the best thresholds of FEV 1 and dyspnea to predict 5-year survival in COPD patients: the COCOMICS study. PLOS ONE 2014 (in press; reference PONE-D-13-39114). 
Figure 1 to accompany Editorial by Soriano and Román-Rodríguez

Andres Iniesta's winning goal against Netherlands in the July 11th, 2010 World Cup Final. [as per www.google.com photo search on February 6, 2014.]

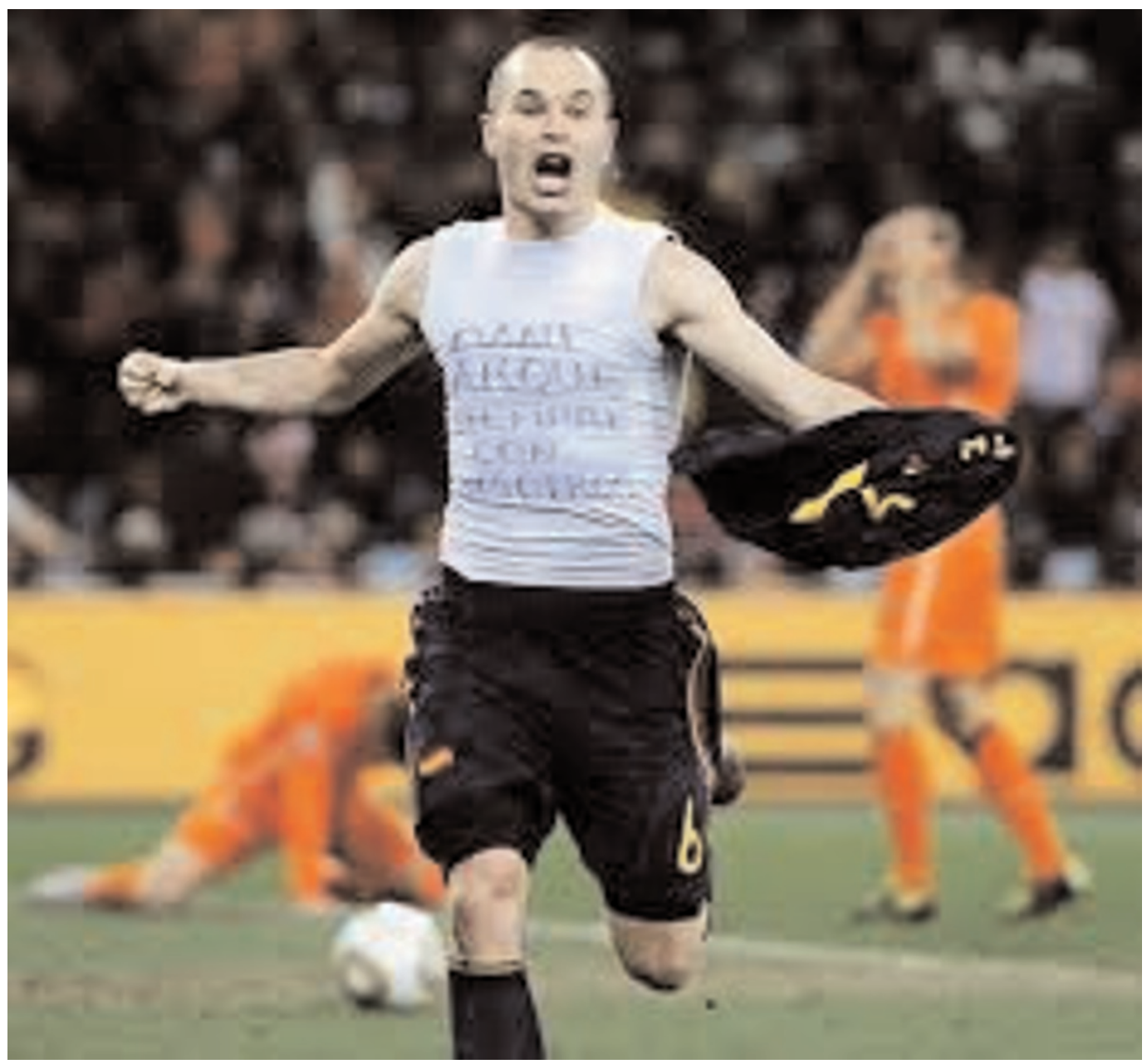

